\title{
A model to predict manufacturing cost for micro-edm drilling
}

\author{
Gianluca D'Urso' ${ }^{1}$ \\ University of Bergamo - DIGIP \\ Viale Marconi 5, 24044 Dalmine (BG) - Italy \\ gianluca.d-urso@unibg.it \\ Mariangela Quarto \\ University of Bergamo - DIGIP \\ Viale Marconi 5, 24044 Dalmine (BG) - Italy \\ mariangela.quarto@unibg.it \\ Chiara Ravasio \\ University of Bergamo - DIGIP \\ Viale Marconi 5, 24044 Dalmine (BG) - Italy \\ chiara.ravasio@unibg.it
}

\begin{abstract}
The recent miniaturization of components in manufacturing has increased the production of lightweight and sophisticated systems in many different industrial fields. Micro Electro Discharge Machining is a technology widely used for these applications. Although it is well known technology, there are still a few research works which investigate the economic implications of this process. This paper reports a model to estimate $\mu E D M-$ machining costs, including fixed and variable costs. The aim of this model is to estimate the overall manufacturing costs, taking into account production and manufacturing process, tool and workpiece information. A process-based cost calculation method is used for this purpose. The model was applied to two case studies based on the execution of micro holes performed on stainless steel and tungsten carbide plates using different electrode materials. The capability of the model was finally demonstrated.
\end{abstract}

\footnotetext{
${ }^{1}$ Corresponding author information can be added as a footnote.
} 


\section{INTRODUCTION}

Worldwide, the progressive reduction of devices and components dimension and the simultaneous integration of functions is a core subject of product development in many different fields of application. This miniaturization process can be considered as a strategic need for the industry and, at the same time, this trend has intensified the development of manufacturing techniques able to achieve these miniaturization purposes $[1,2]$.

One of the most extensively technology used to reach the components miniaturization is the micro-EDM. In this non-conventional technology, the material is removed by discharging electric current generated in the gap between the tool electrode and the workpiece. This technology has many advantages, in fact, the workpiece is not subjected to mechanical deformation as there is no physical contact between the tool and the workpiece; it allows to manufacture complex shapes with very high accuracy $[3,4]$.

Despite of the great development of this process, today there is a limited research activity about the cost of its use. This is a very important gap for this research fields, in fact, goods cost estimation has a direct bearing on the performance and effectiveness of a business enterprise because overestimation can result in loss of business and goodwill in the market, whereas underestimation may lead toward financial losses to the enterprise. Cost estimation has been a focal point for design and operational strategies and a key agenda for managerial policies and business decisions. As a result, a substantial research effort has been expanded in exploring design 
implications, new techniques and methods for producing accurate and consistent cost estimates not only to generate optimum design solutions, but also to achieve the maximum customer satisfaction in terms of low-cost, high quality and in-time product delivery $[5,6]$.

The literature about cost estimation of general mechanical process covers issues from manufacturing cost estimation of standard mechanical components to cost analysis of complex products [5], but just few research is about a specific method to overhead costing for the micro-EDM process.

E. M. Shehab et al. [7] developed an intelligent knowledge-based system that accomplished an environment to assist inexperienced users to estimate the manufacturing cost modelling of a product at the conceptual design stage of the product life cycle. They discussed the development process of the proposed system for the cost modelling of machining processes.

D. Ben-Arieh et al. [8] presented a method to use Activity Based Cost (ABC) to evaluate the cost of the design and development activities for machined parts. The methodology was demonstrated on a sample part being produced in a controlled manufacturing facility. They classified cost estimation methods into intuitive, analogical, parametric and analytical.

L. H. S. Luong at al. [9] described the development and implementation of a generic knowledge-based system for process planning and cost estimation in the hole making process. The main function of the system, besides estimating the cost of 
production, is to recommend appropriate processes, their sequence and their respective machining conditions in order to obtain the required product specifications.

S. Rehman et al. [10] describes a method for modelling costs during all the design phase of a product's life-cycle, from concept to detail design. This approach to design evaluation has the advantages of allowing management to make a more accurate bid estimates, encouraging designers "to design to cost" and reducing the amount of design rework, hence reducing the product's time to market and controlling product cost. The cost modelling strategy adopted incorporates the use of knowledge-based and case-based approaches.

In this paper a model to estimate micro EDM machining costs was developed. This model was used in a case study to demonstrate its capability. The case study considers a drilling application of stainless steel using two types of electrodes.

\section{ASSESSMENT MODELLING METHODOLOGY}

The aim of the model cost developed in this research is to estimate the overall manufacturing costs, taking into account production and manufacturing process, tool and workpiece information.

A process-based cost calculation method is used to build the cost model. The total cost is divided in two different categories and the cost associated with each category is calculated based on the associated process steps. As illustrated in Fig. 1, the main cost categories considered for the modelling are fixed costs, which include 
ownership, routine maintenance and variable costs, which include labour cost, extraordinarily maintenance, utilities costs, tool and workpiece.

\section{Fixed costs}

Fixed costs are those expenses that are more or less independent of the level of activity of the machine and the output. These remain constant throughout the relevant range and are usually considered sunk for the relevant range (not relevant to output decisions). The most common fixed costs are presented below.

Ownership cost is the most significant fixed cost, as those payments are due whether or not you run the machine. Most machines are financed with a fixed monthly payment and often it is not referred to cost management, in order to fully recover the cash flows for the monthly payments. In some cases, it might be useful to estimate the economic life of the machine and divide its cost to this value, but most EDM machines have a limited residual value at the end of their economic life, so this factor can often be omitted [11]. The most affecting aspects to calculate the cost of ownership are accrued interest and the amortization, taking into account the coefficient of depreciation of tangible assets. The annual amortization is calculated and it is added to passive interests.

Routine maintenance includes all the maintenance actions performed regularly to prevent disruption of the system or the component. This is slightly affected by the level of activity of the machine for most installations.

\section{Variable costs}


Variable costs are those that vary depending on a company production volume, they rise as production increases and fall as production decreases. Variable costs differ from fixed costs, which tend to remain the same regardless production output. These costs include wages, utilities, materials, etc. There is the most substantial component of the total machining costs. The variable costs are presented below.

Labour cost (Eq. 1) can be direct or indirect. Direct costs include wages for the employees physically making a product, like workers on an assembly line. Indirect costs are associated with support labour, such as employees that maintain factory equipment but do not operate the machines themselves. In this case, labour cost includes the operator wage rate and overhead. The operator's overhead includes training cost, contributions, medical and other fringe benefits. This is estimated as $60 \%$ of the wage rate [12]. The labour costs depend on the amount of operator attention. In general, it could be written as Eq. 1:

$C_{L}=(w g+60 \% w g) \cdot n_{p} \cdot t$

where:

- $\quad C_{L}$ is the total labour cost $[€]$;

- $\quad w g$ is the wage rate of manufacturing personnel $[€ / h]$;

- $\quad n_{p}$ is the number of manufacturing personnel;

- $\quad t$ is the total time needed for machining. It encloses $33 \%$ of machining time, setup time and design time [h]. 
Extraordinary maintenance (Eq. 2) work performed on a part of system to increase its useful life by over a year. It includes problem detection and failure correction. The total cost of extraordinary machining is calculated considering the cost of damage of experts necessary to the failure correction (Eq. 2).

$$
C_{M}=C_{r}+n_{\exp } \cdot C_{h \exp } \cdot t_{r}
$$

where:

- $\quad C_{M}$ is the total cost of extraordinary maintenance $[€]$;

- $\quad C_{r}$ is the cost of replacement [€];

- $\quad n_{\text {exp }}$ is the number of experts necessary to solve the problem;

- $\quad C_{h \exp }$ is the expert hourly cost $[€ / \mathrm{h}]$;

- $\quad t_{r}$ Is the time needed for the failure correction [h].

Utilities cost (Eq. 3) includes the costs of all the utilities needed to work the machine. It includes the cost of water, electricity and dielectric fluid. All these costs are calculated considering the quantity of utility used during the machining and their unit costs.

$C_{U}=n_{w} C_{w}+n_{e} C_{e}+n_{d} C_{d}$

Where:

- $\quad C_{U}$ is the total utilities cost $[€]$;

- $\quad n_{w}$ is the quantity of water used $\left[\mathrm{m}^{3}\right]$;

- $\quad C_{w}$ is the unit cost of water $\left[€ / \mathrm{m}^{3}\right]$;

- $\quad n_{e}$ is the quantity of electricity used [kWh];

- $\quad C_{e}$ is the unit cost of electricity [€/kWh]; 
- $\quad n_{d}$ is the quantity of dielectric fluid used [L];

- $\quad C_{d}$ is the unit cost of dielectric fluid [€/L].

Tool cost includes the purchase of tools for the machining. Micro EDM presents two types of tool: electrode and wire. The cost of each electrode depends from the material (brass, tungsten carbide, copper, etc.), geometry (tube, coreless, hole star shape, etc.) and diameter. From the user point of view, the electrode cost for the is directly influenced by the tool wear while the wire cost is calculated considering the feed rate to establish the amount of wire used during the machining. In some case the two tools (electrode and wire) can coexisted at the same time, for example, when the electrode was dressed to reduce the diameter.

\section{CASE STUDIES}

In order to validate the model, two case studies were used to demonstrate its capability. The case studies presented a cost analysis of micro EDM drilling and it took into account only few significant variable costs.

The study considered the machining presented by G. D'Urso et al. [13] for the execution of micro holes on a stainless steel plates (AISI 304) having a thickness equal to $3 \mathrm{~mm}$ and the machining presented by G. D'urso et al. [14] for the execution of micro holes on a tungsten carbide plates. Both machining were executed by means of tubular electrode made of two different materials (tungsten carbide and brass) having an external diameter equal to $0.3 \mathrm{~mm}$ and an internal diameter equal to $0.12 \mathrm{~mm}$. Hydrocarbon oil was used as dielectric. The experimental campaign was carried out by varying several 
process parameters such as peak current (I), voltage (V) and frequency (F), in order to study the relation between the process parameters and the machining performance such as Material Removal Rate (MRR) and Tool Wear Ratio (TWR).

For each tool material type, the combination of the process parameters and the experimental sequence were defined basing on a design of experiment (DOE) with three levels and five repetitions. Moreover, in order to study the progress in the drilling process, each hole was carried out in several substeps having the same drilling tool displacement. For each combination workpiece/electrode materials, progressive MRR and TWR technology windows were elaborated to predict the performance as a function of the drilling depth. From these data $[13,14]$, it was possible to elaborate progressive machining time and tool wear technology windows.

\section{Stainless Steel plates}

For the cost estimation, it was considered the execution of 100 holes. The following hypothesis were assumed: machining setup is equal to $1.5 \mathrm{~h}$ (start-up, centering, preparation of electrode and workpiece, setup process parameters), operator's wage is equal to $25 € / \mathrm{h}$ and the operator monitors the machine only partially during the processing (e.g. 33\%). Fig. 2 and Fig. 3 show the trend of machining time and tool wear respectively for the execution of a single micro hole on stainless steel plate, varying the process parameters as a function of the hole depth for two electrode materials. In particular, Fig. 2 shows the comparison of the progressive machining time technology window for tungsten carbide and brass electrode. The limits of each region 
is defined by the process conditions giving rise to the minimum and maximum. In Fig. 3, the limits of each area defined by the process conditions giving rise to the minimum and maximum of tool wear. The trend of the interpolating equations for each condition is linear with a correlation index higher than $99 \%$.

The machining time function was inserted into the equation used to calculate the labour cost (Eq. 1) and the utilities cost (Eq. 3). After the estimation of these costs, the sum of labour and utility costs was calculated. Fig. 4 shows the area in which the cost changes as a function of both hole depth and the electrode material. The cost is higher for the machining conducted with tungsten carbide electrode. This difference is due to the duration of machining; in fact, the machining performed with brass electrode is faster than the others regardless of the technologies used. The plot shows that the tungsten carbide machining has a greater window in which the cost varies.

To estimate the tool electrode costs, the unit cost of electrode was calculated considering the price lists equal to $0.03 € / \mathrm{mm}$ for tubular brass electrode and 0.12 $€ / \mathrm{mm}$ for tubular tungsten carbide electrode.

To calculate the cost of tool wear the angular coefficient of the curve reported in Fig. 2 was multiplied for the unit cost of electrode and for the number of holes performed during the experimental campaign. Fig. 5 shows the tool cost estimation for the execution of 100 holes on stainless steel plate using two types of electrode as a function of the drilling depth. The tungsten carbide area is always higher than the brass one because the first electrode is more expensive than the second one even though the tool wear of brass is higher than the tungsten carbide. 
From the figure is clear that both labour+utilities cost and tool cost calculated for the machining performed by the brass electrode are always smaller than the cost estimated for the tungsten carbide electrode and the window described by the brass electrode machining are always closer than the other one.

Brass has higher tool wear than tungsten carbide but it permits to have higher MRR. Despite brass has a high level of tool wear, its low price and its high MRR make it competitive with respect to tungsten carbide. It is important to remark that where the accuracy is required, tungsten carbide electrode is the best solution. Fig. 6 clearly shows that when the hole depth increases, the total cost is characterized by a constant growth, directly proportional to the depth. In particular, the subtended area of tungsten carbide electrode for stainless steel plate grows more quickly than the brass electrode ones. Within the limits of the tested conditions, a general scheme for the prediction of the variable cost was obtained.

\section{Tungsten Carbide}

In this section, the experimental campaign performed on a tungsten carbide plates is taken into account. The progressive machining time (Fig.7) and the tool wear (Fig.8) technology window were elaborate from the data reported in [14].

The limits of each region are defined by the process conditions giving rise to the minimum and maximum machining time and tool wear. The behaviours of tungsten carbide and brass electrodes are interpolated by a linear curves $\left(R^{2}>98 \%\right)$. Regarding the machining time, since brass electrode had a higher electrical conductivity and commonly requires higher power discharge, it permits to obtain faster micro-holes. For 
the tool wear, tungsten carbide electrode, having a higher melting temperature than brass, was subjected to a minor wear; the wide technology window of brass electrode corroborates its sensitivity to the hole depth.

For the cost estimation, it was considered the execution of 100 holes.

The same previous hypothesis and procedure used in section 3.1 were assumed.

Fig. 9 shows the trend of the labour+utilities cost obtained considering two electrode materials as a function of the hole depth. Using tungsten carbide electrode, the costs are higher than the ones obtained using the brass electrode, due to the high tool wear.

Fig. 10 shows the tool cost trend. In general, tool cost using tungsten carbide electrode is higher than the one obtained using brass electrode. Moreover, in this case, the two areas are partially overlapped. It means that for few technologies, from only the tool cost point of view, there are no differences using the two electrode materials.

For the machining of tungsten carbide plate (Fig. 11), the total cost has a smaller slope than the other machining and in general, the total cost for the machining on stainless steel plate is higher than the total cost for the machining on tungsten carbide plate.

\section{Comparison}

New comparison plots were built. These new plots (Fig. 12, Fig. 13) represent the windows in which, machining time and tool wear vary during the machining for some sample depth when the machining technology changes. In this specific case depth equal to $1-2-3-\mathrm{mm}$ is considered. 
The plots show how the variability changes when the hole depth increases. A different variability is present in the cost estimation. In particular, in all cases, the wide of the window changes but it always increased when hole depth grows.

Considering the machining time, it is possible to observe that that the variability of machining performed on tungsten carbide plates by tungsten carbide electrode is smaller than the machining performed on stainless steel plates. The tungsten carbide electrode wear has the same variability in both machining. On the contrary, the situation of the brass electrode wear is very different, if the machining is performed on a tungsten carbide plates, the window is wider than the previous machining. The tool wear is almost five times higher than the previous one.

Fig. 14 shows a total cost comparison as a function of machining depth for all combination of workpiece and electrode material. Tungsten carbide electrode uses to machine the stainless steel plates is the most expensive combination with a high variability for each depth. the other combinations (workpiece-electrode material) have a similar width and the window covere analogue range of cost.

\section{CONCLUSIONS}

A model for the cost estimation of micro-EDM drilling, considering both fixed and variable costs, was presented. To demonstrate the capability of the model, two case studies were considered taking into account only variable costs. In particular, micro holes on stainless steel and on tungsten carbide plates using two types of electrode materials varying the electrical process parameters, were performed. The effect of the 
hole depth on the costs was investigated and it was found that total cost had a linear trend as a function of the hole deep in both workpiece material with a different slope. The total variable costs obtained using tungsten carbide electrode were always higher than that obtained using brass electrode. Moreover, increasing the hole depth, for the stainless steel workpiece, the cost using tungsten carbide electrode increased more quickly than that obtained for brass electrode; for the tungsten carbide workpiece, the difference between the two electrodes was lower. Despite brass electrode had a high level of tool wear, its low price and its high MRR made it competitive with respect to tungsten carbide one.

This model can be applied to others combinations workpiece-electrode materials and can be useful to determine the cost operation in an industrial field. 
Insert ASME Journal of Manufacturing Science and Engineering

\section{NOMENCLATURE}

$D_{\text {bottom }} \quad$ Bottom diameter of the hole

Delectrode Electrode tool diameter

$D_{\text {ext }} \quad$ Nominal electrode outer diameter

$D_{\text {int }} \quad$ Nominal electrode inner diameter

$D_{\text {top }} \quad$ Top diameter of the hole

DOC Diametrical Overcut

DOE Design of Experiment

EDM Electro-Discharge Machining

h Hole depth

MRR Material Removal Ratio

$M R_{\text {tool }} \quad$ Material removed from tool electrode

$M R_{w p} \quad$ Material removed from workpiece

$t \quad$ Machining time 


\section{REFERENCES}

[1] Hesselbach, J., Raatz, A., Wreg, J., Herrmann, H., Illenser, S., 2004, "International State of the Art of Micro Production Technology", Production engineering, 11, pp. 2936.

[2] D'Urso, G., Maccarini, G., Merla, C., 2013, "The Downsizing Effects in EDM Drilling of Micro Holes", Key Engineering Materials, 549, pp. 503-510. DOI:

10.4028/www.scientific.net/KEM.549.503

[3] Kadirvel, A., Hariharan, P., Gowri, S., 2012, "A review on various research trends in micro-EDM", Int. J. Mechatronics and Manufacturing Systems, 5(5-6), pp. 361-384. DOI: 10.1504/IJMMS.2012.049968

[4] Mohd Abbas, N., Solomon, D. G., Bahari, Md. F., 2007, "A review on current research trends in electrical discharge machining (EDM)", Int. J. Mach. Tool. Manuf., 47(7-8), pp. 1214-1228. DOI: 10.1016/j.ijmachtools.2006.08.026

[5] Niazi, A., Dai, J. S., Balabani, S., Seneviratne, L., 2006, "Product Cost Estimation: Technique Classification and Methodology Review", J. Manuf. Sci. Eng., 128, pp: 563575. DOI: $10.1115 / 1.2137750$

[6] Shehab, E., Abdalla, H., 2002, “An Intelligent Knowledge-Based System for Product Cost Modelling", Int. J. Adv. Manuf. Technol., 19(1), pp. 49-65. DOI: 10.1007/PL00003967

[7] Shehab, E.M., Abdalla, H.S., 2001, “Manufacturing cost modelling for concurrent product development", Robotics and Computer Integrated Manufacturing, 17(4), pp. 341-353. DOI: 10.1016/S0736-5845(01)00009-6

[8] Ben-Arieh, D., Qian, L., 2003, “Activity-based cost management for design and development stage", Int. J. Production Economics, 83(2), pp. 169-183.

[9] Luong, L. H. S., Speddingt, T., 1995, “An Integrated System for Process Planning and Cost Estimation in Hole Making", Int. J. Adv. Manuf. Technol., 10, pp. 411-415. DOI: 10.1016/S0925-5273(02)00323-7

[10] Rehman, S., Guenov, M. D., 1998, “A methodology for modelling manufacturing costs at conceptual Design", Computers ind. Engng, 35(3-4), pp. 623-626. DOI: 10.1016/S0360-8352(98)00174-0

[11] Kern, R., 2007 “CNC EDM-Cost analysis”, Techtips. 
[12] Yeo, S. H., Ngoi, B. K. A. , Poh, L. S., Hang, C., 1997, “Cost-Tolerance Relationships for Non-Traditional Machining Processes", Int. J. Adv. Manuf. Tech., 13, pp. 35-41. DOI: 10.1007/BF01179228

[13] D'Urso, G., Maccarini, G., Ravasio, C., 2014, "Process performance of micro-EDM drilling of stainless steel”, Int. j. Adv. Manuf. Tech., 72, pp. 1287-1298. DOI: 10.1007/s00170-014-5739-1.

[14] D'urso, G., Ravasio, C., 2016, "Performance evaluation of micro-EDM drilling process of tungsten carbide". 
Insert ASME Journal of Manufacturing Science and Engineering

\section{Figure Captions List}

Fig. 1 Contributors to product manufacturing costs.

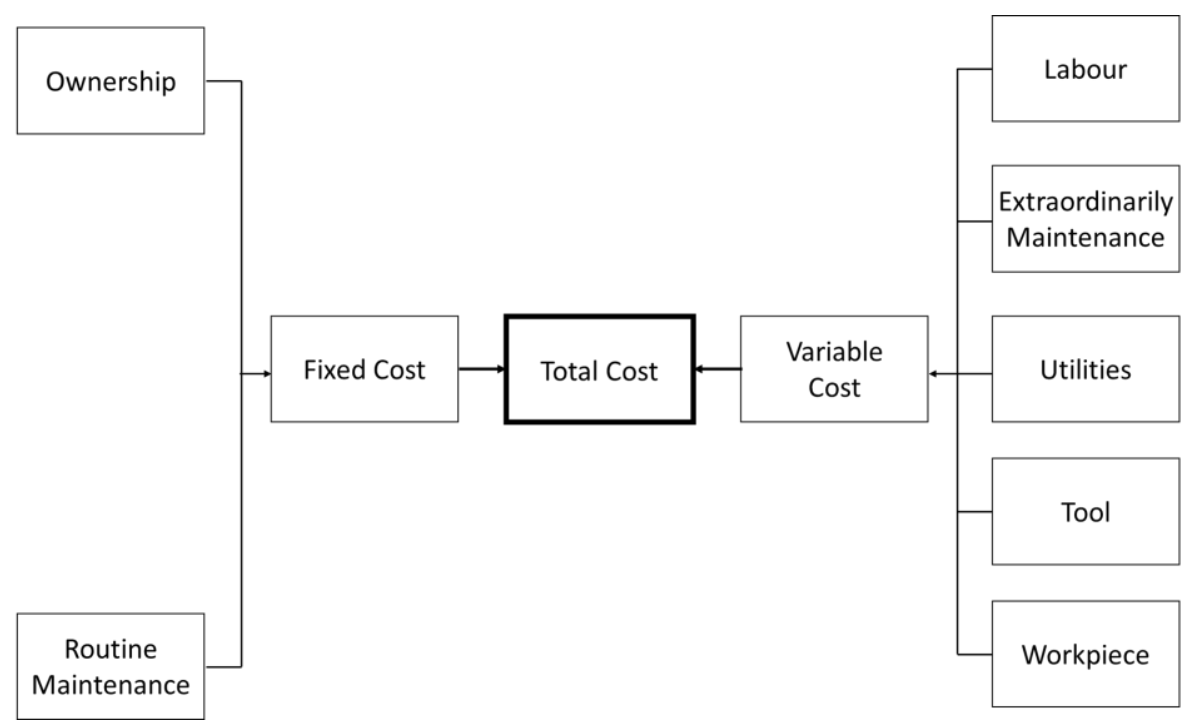


Fig. 2 Machining time for a single hole on stainless steel plates, varying the process parameters, as a function of the holes depth for two electrode materials.

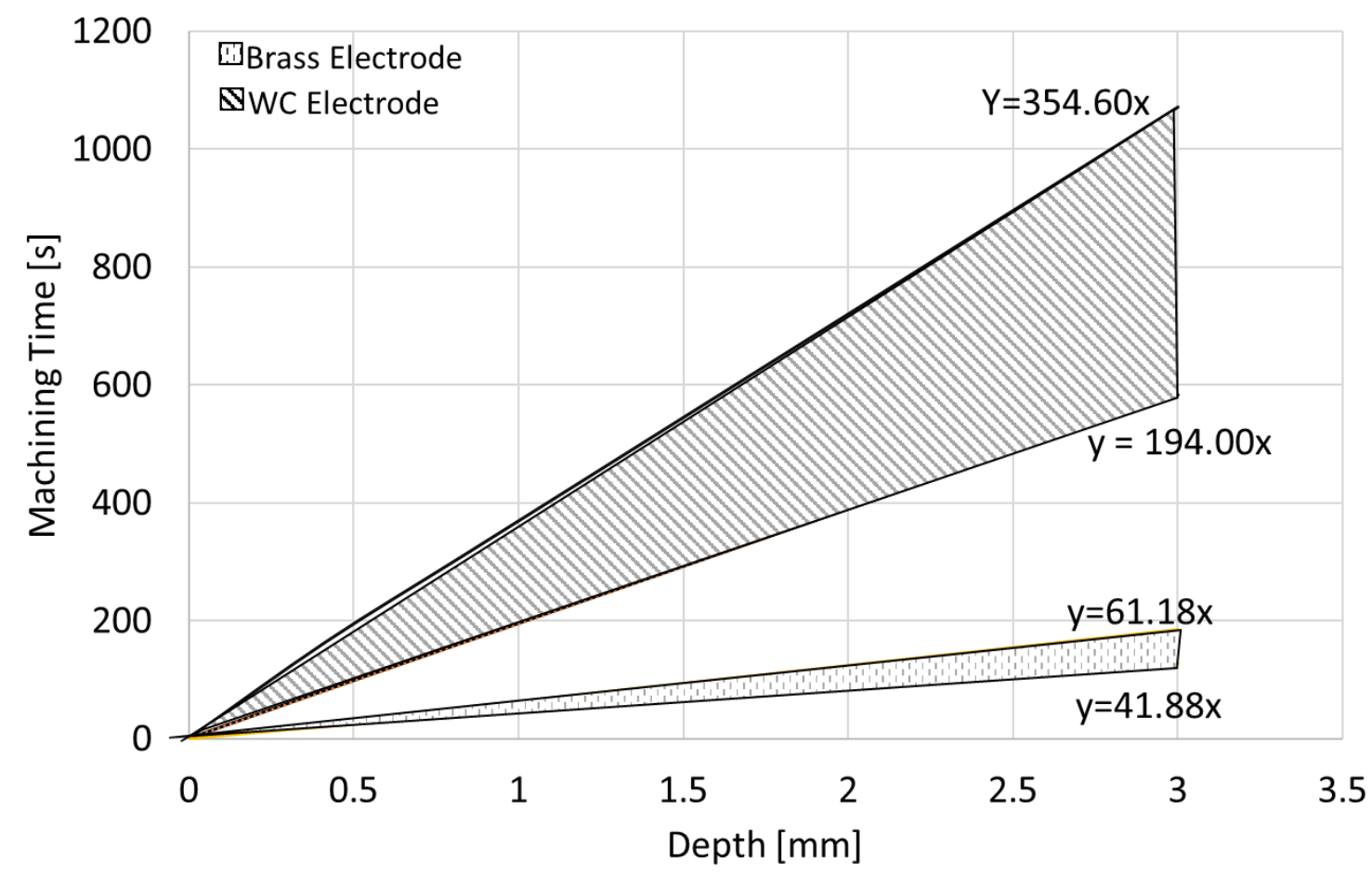


Insert ASME Journal of Manufacturing Science and Engineering

Fig. 3 Tool wear for a single hole on stainless steel plates, varying the process parameters, as a function of the holes depth for two electrode materials [13].

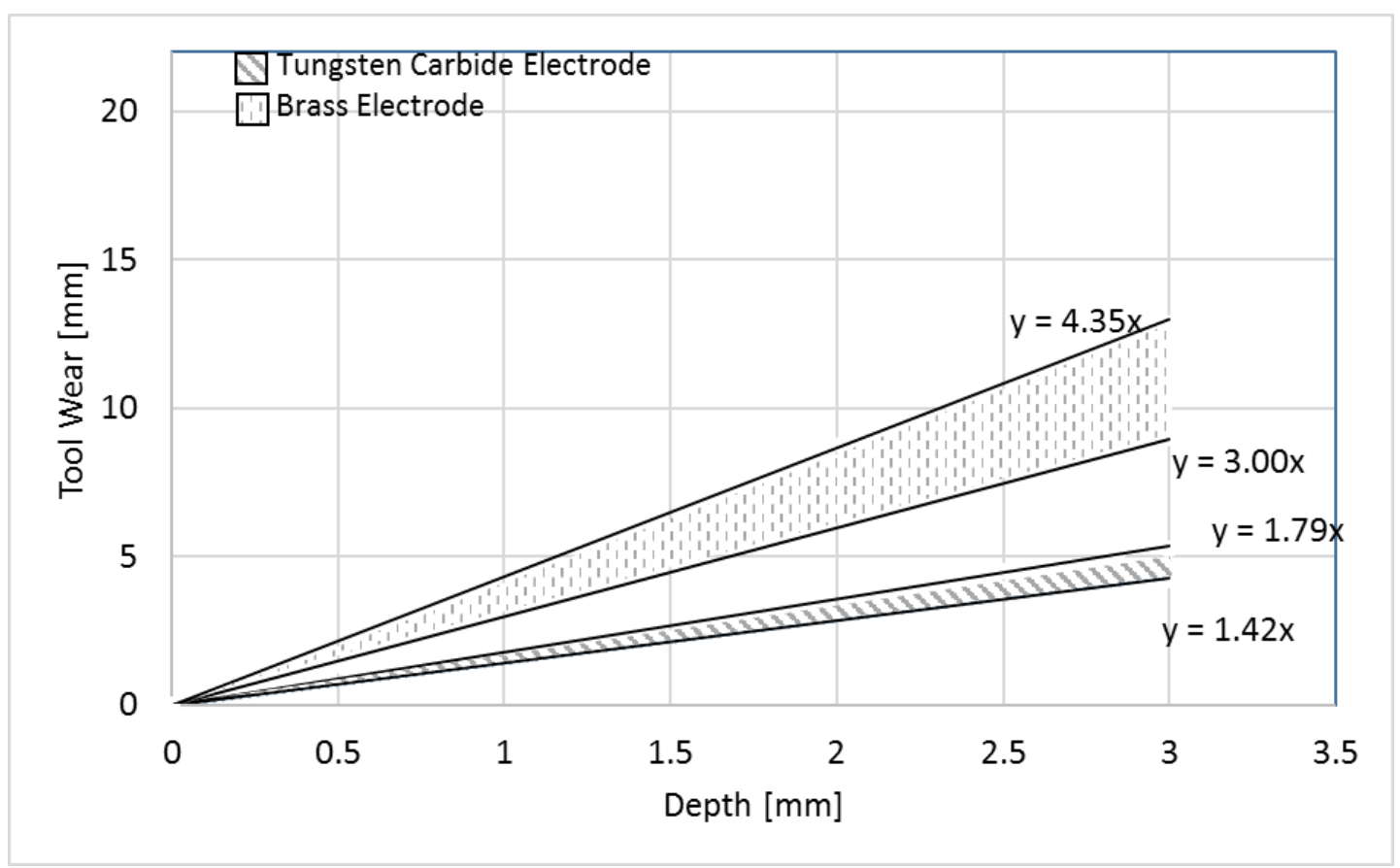


Fig. 4 Labour cost + utilities costs as a function of the drilling depth varying the electrode materials for 100 holes performed on stainless steel plate.

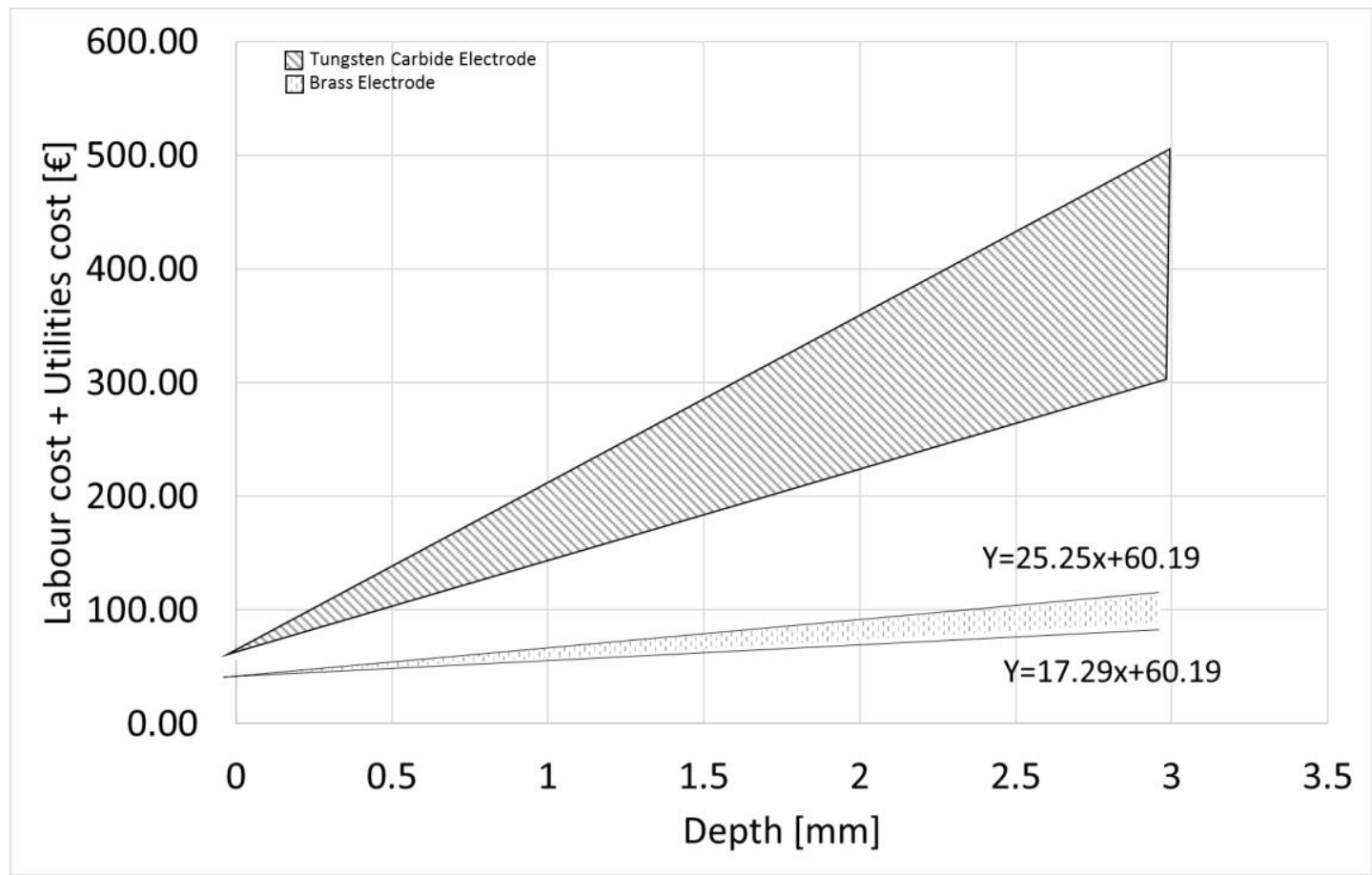


Fig. 5 Tool cost as a function of the drilling depth varying the electrode materials for 100 holes performed on Stainless steel.

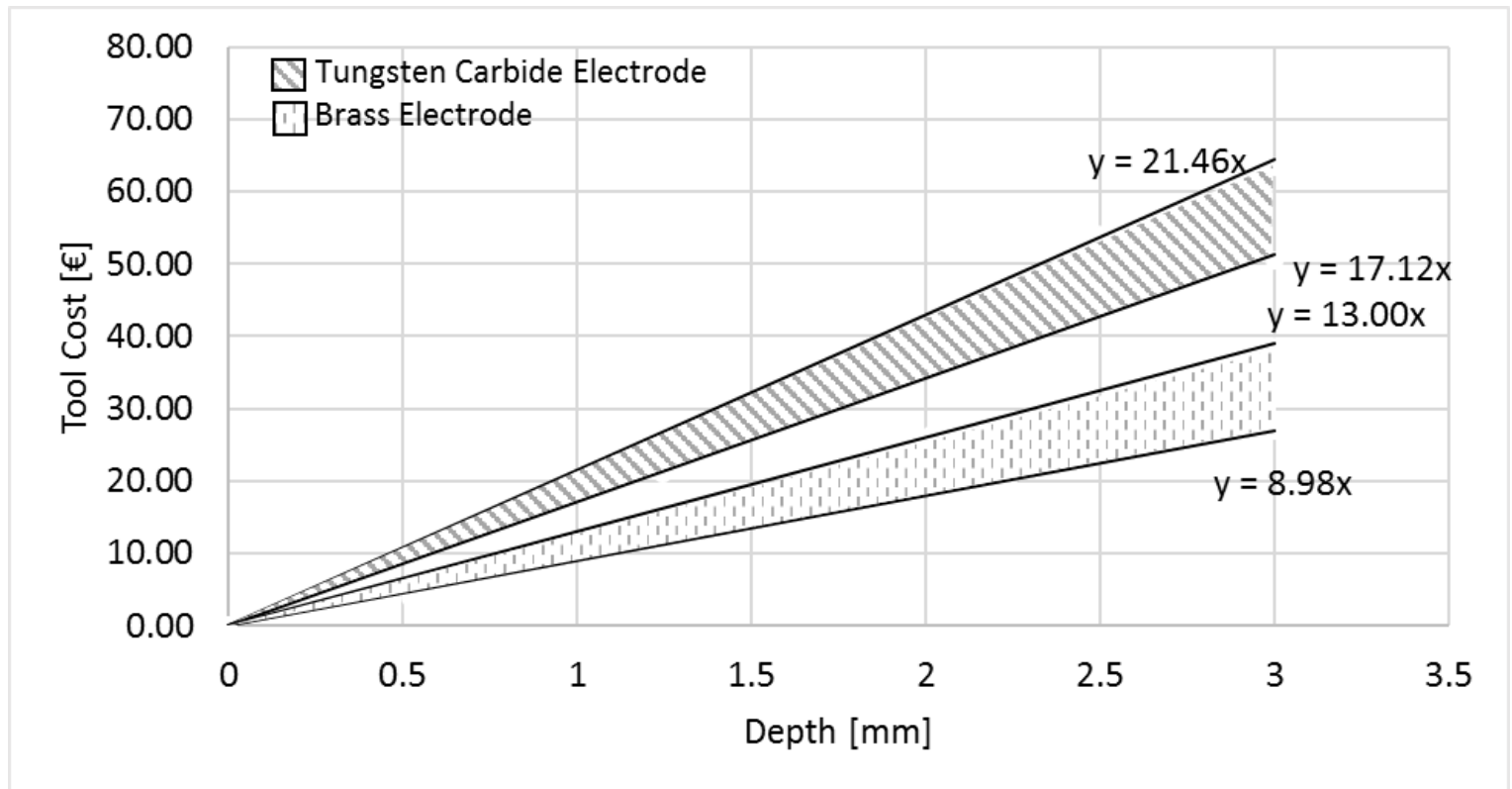


Fig. 6 Total variable cost for the execution of 100 holes varying the electrode material as a function of the hole depth performed on stainless steel plate.

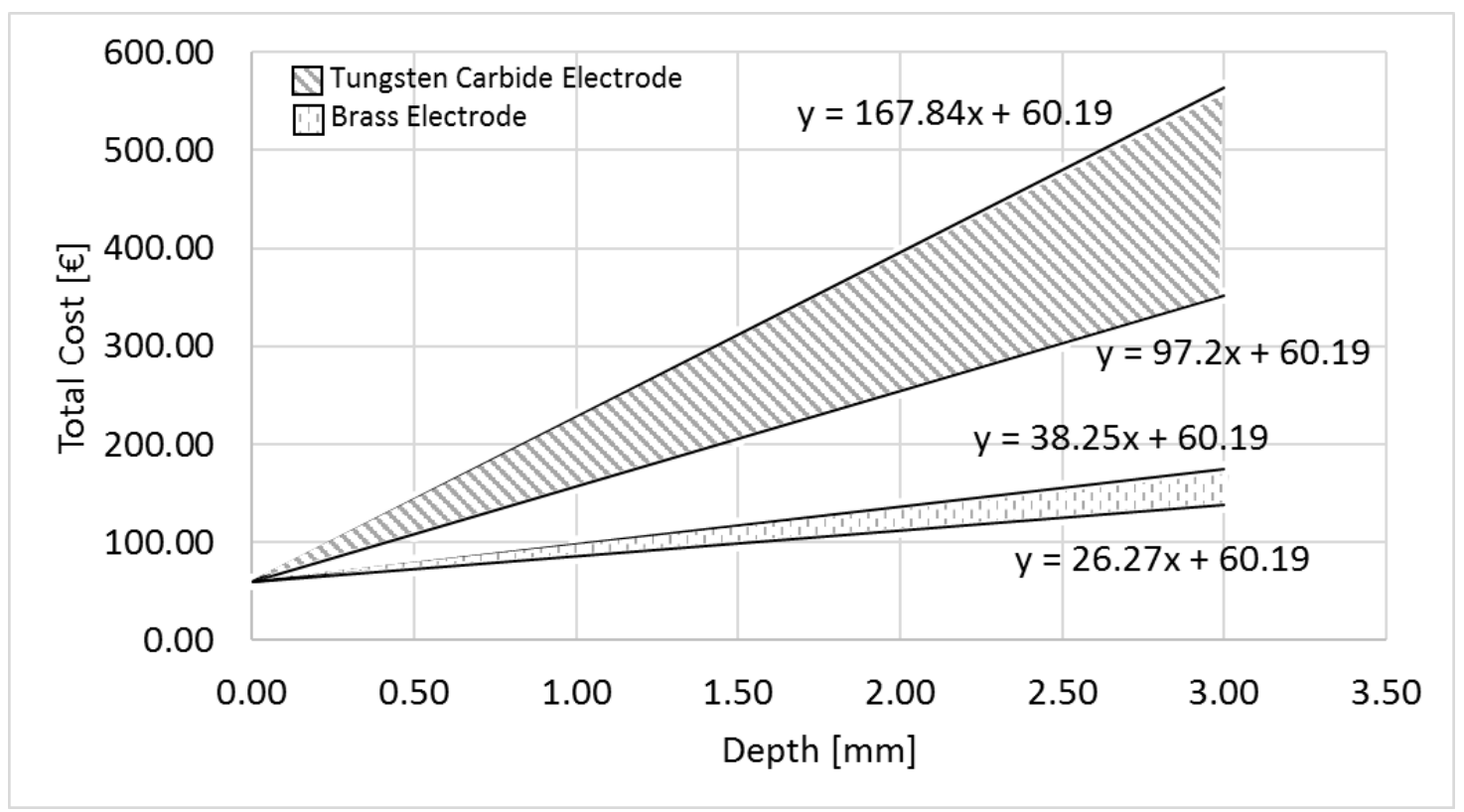


Fig. 7 Machining time for a single hole on tungsten carbide plates, varying the process parameters, as a function of the holes depth for two electrode materials.

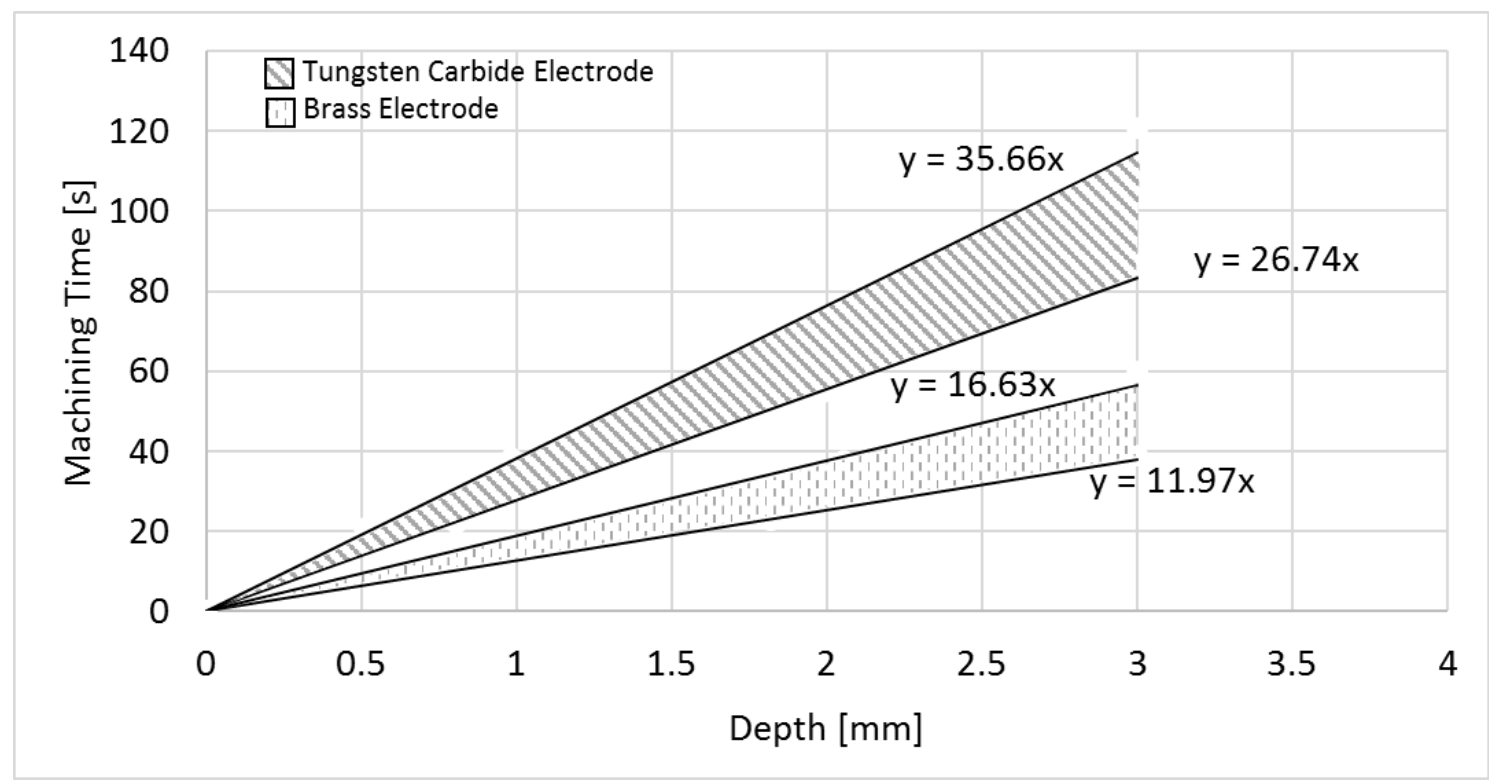


Fig. 8 Tool wear for a single hole on tungsten carbide plate, varying the process parameters, as a function of the holes depth for two electrode materials.

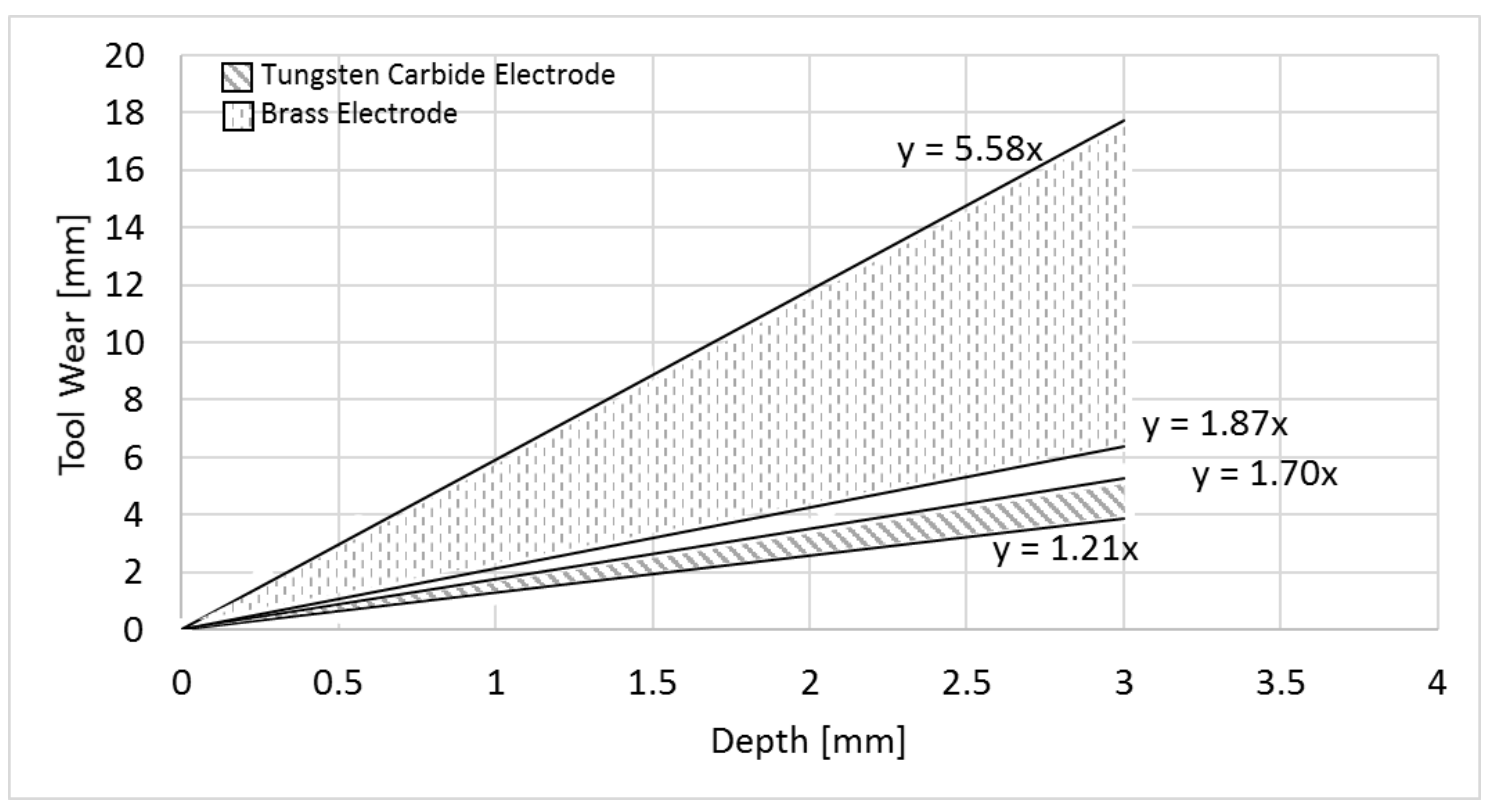


Fig. 9 Labour cost + utilities costs on tungsten carbide plate as a function of the drilling depth varying the electrode materials for 100 holes.

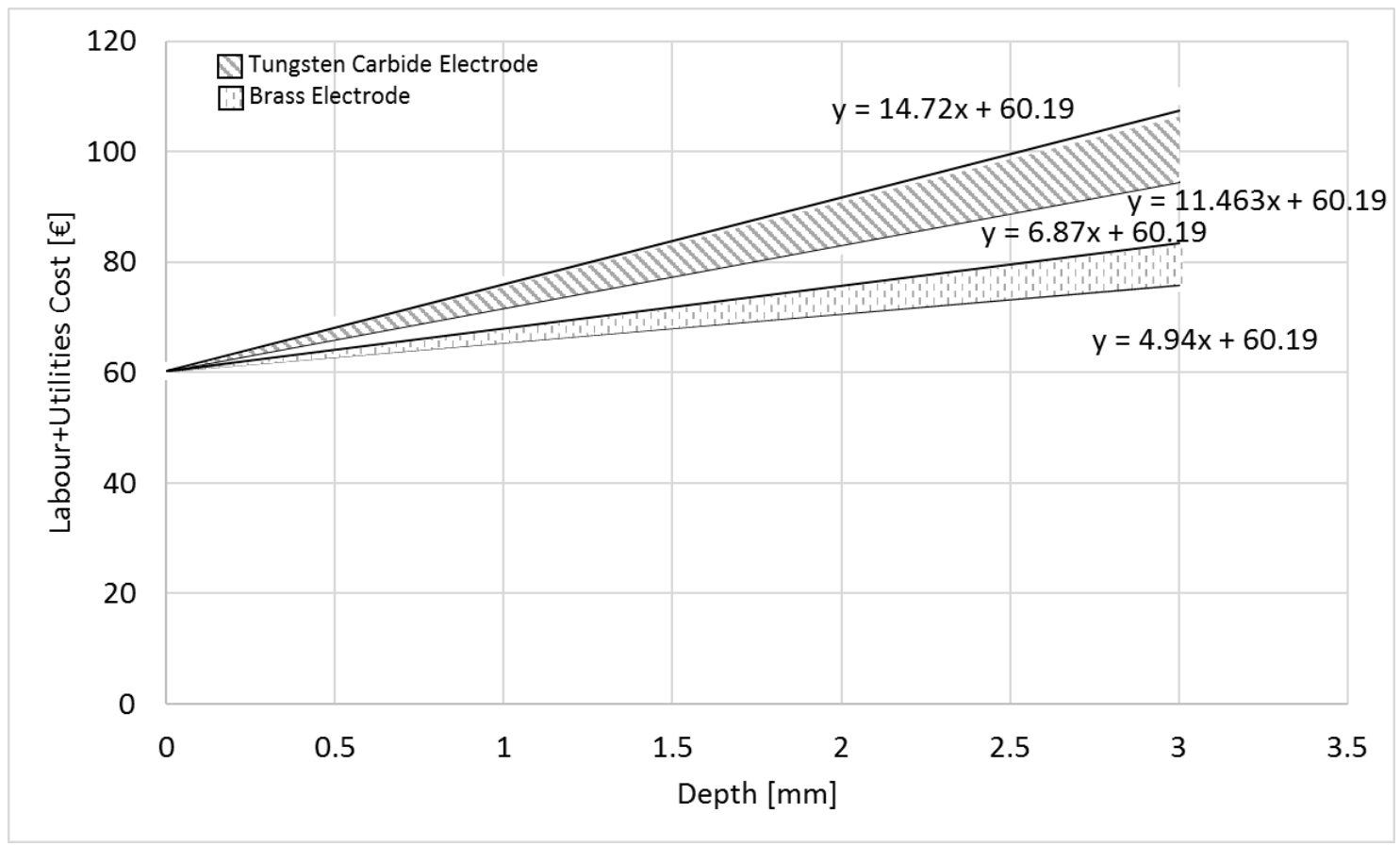


Fig. 10 Tool cost as a function of the drilling depth varying the electrode materials for 100 holes performed on tungsten carbide plate.

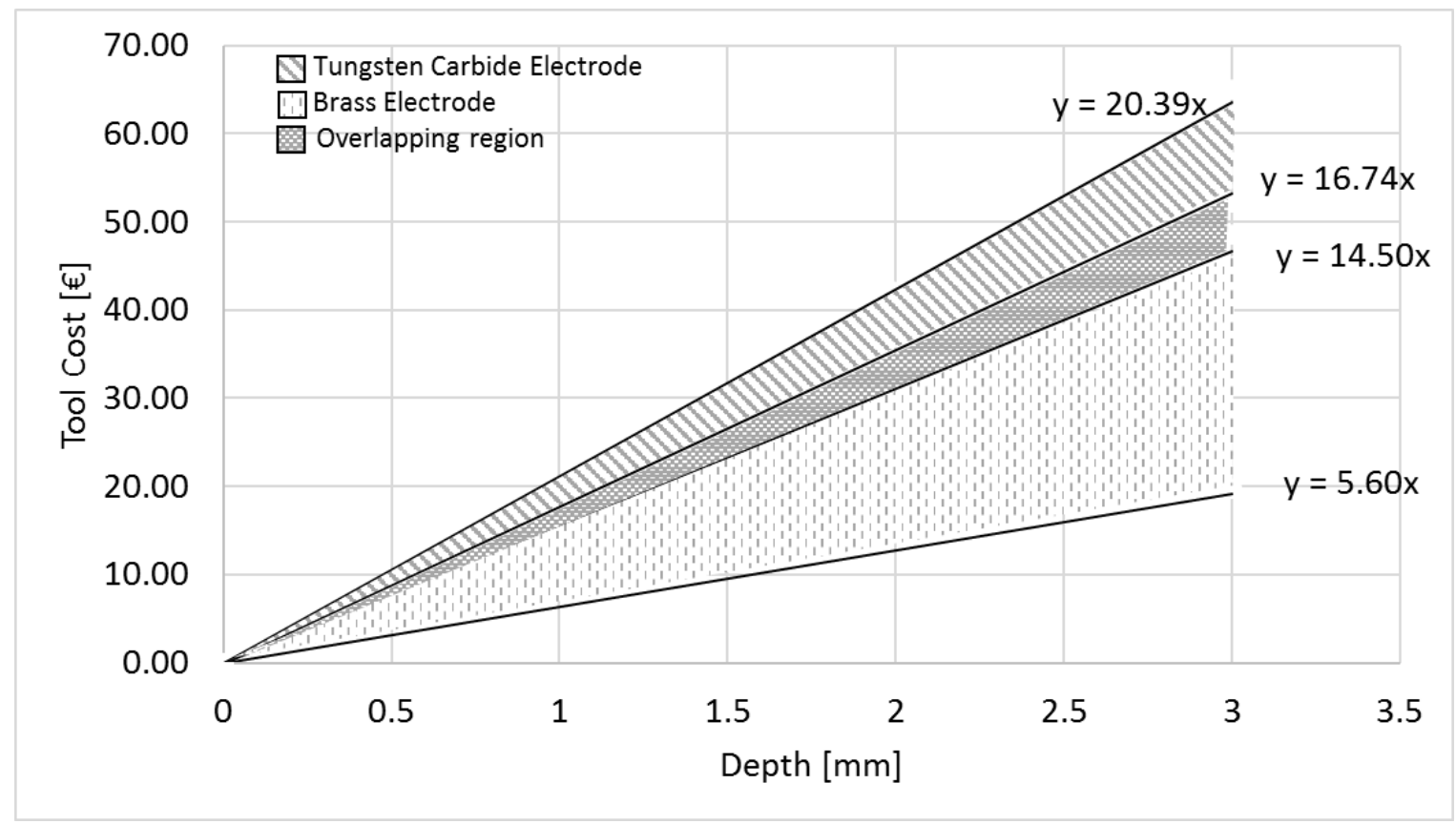


Fig. 11 Total variable cost for the execution of 100 holes varying the electrode material as a function of the hole depth performed on tungsten carbide plate.

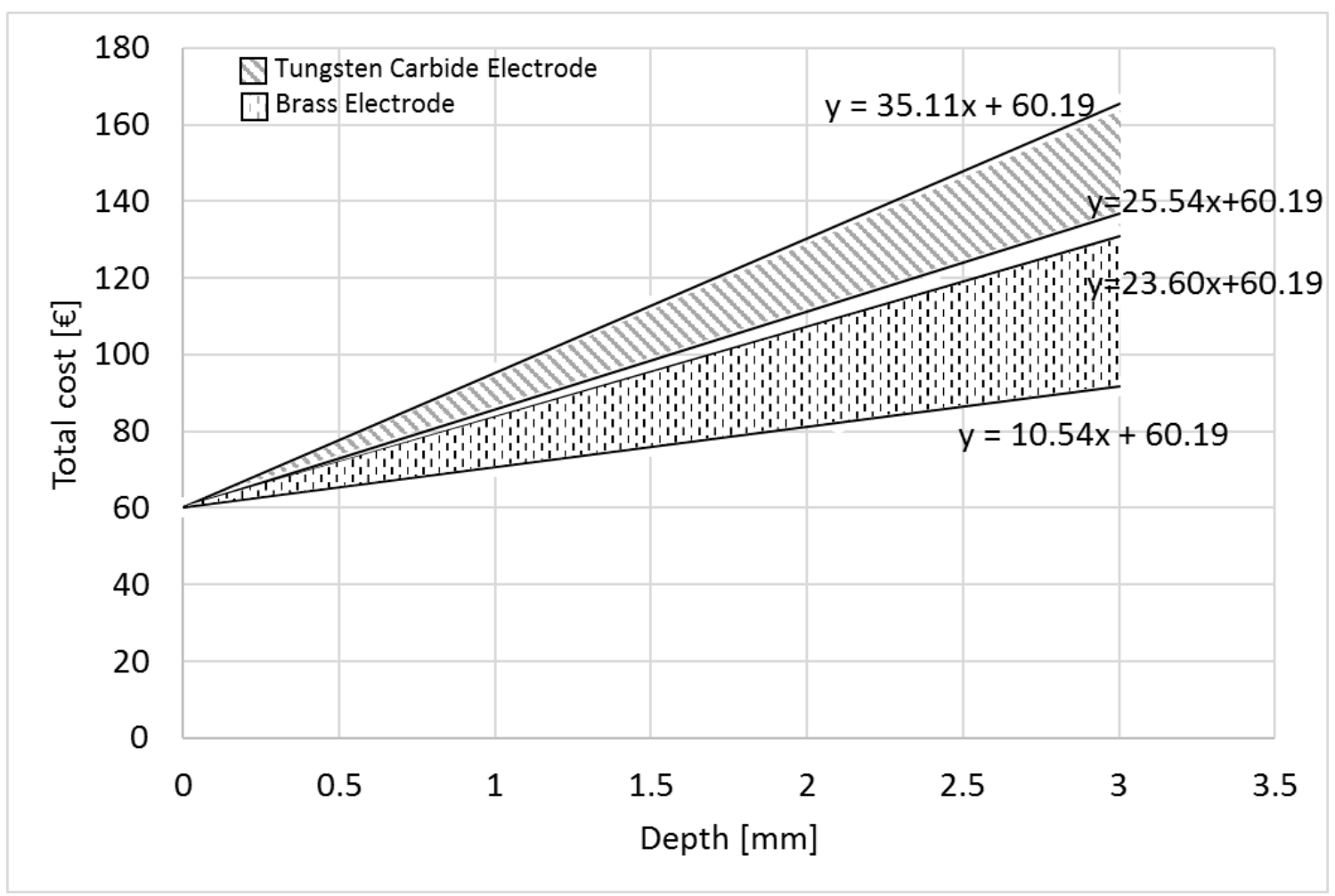


Insert ASME Journal of Manufacturing Science and Engineering

Fig. 12 Machining time comparison as a function of the machining depth for all the combination workpiece-electrode.




Fig. 13 Tool wear comparison as a function of the machining depth for all the combination workpiece-electrode.




Fig. 14 Total cost comparison as a function of the machining depth for all the combination workpiece-electrode.



